\title{
Corrigendum to "Functional Virtual Flow Cytometry: A Visual Analytic Approach for Characterizing Single-Cell Gene Expression Patterns"
}

\author{
Zhi Han, ${ }^{1,2}$ Travis Johnson, ${ }^{2}$ Jie Zhang, ${ }^{2,3}$ Xuan Zhang, ${ }^{1}$ and Kun Huang ${ }^{2}$ \\ ${ }^{1}$ College of Software, Nankai University, Tianjin, China \\ ${ }^{2}$ Department of Biomedical Informatics, The Ohio State University, Columbus, OH, USA \\ ${ }^{3}$ The CCC Biomedical Informatics Shared Resource, The Ohio State University, Columbus, OH, USA \\ Correspondence should be addressed to Kun Huang; kun.huang@osumc.edu
}

Received 18 October 2017; Accepted 26 October 2017; Published 13 November 2017

Copyright (C) 2017 Zhi Han et al. This is an open access article distributed under the Creative Commons Attribution License, which permits unrestricted use, distribution, and reproduction in any medium, provided the original work is properly cited.

In the article titled "Functional Virtual Flow Cytometry: A Visual Analytic Approach for Characterizing Single-Cell Gene Expression Patterns" [1], an acknowledgment should be added as follows:

The work was also partially supported by the Shenzhen Peacock Plan (KQTD2016053112051497 to Kun Huang).

\section{References}

[1] Z. Han, T. Johnson, J. Zhang, X. Zhang, and K. Huang, "Functional virtual flow cytometry: a visual analytic approach for characterizing single-cell gene expression patterns," BioMed Research International, vol. 2017, Article ID 3035481, 9 pages, 2017. 

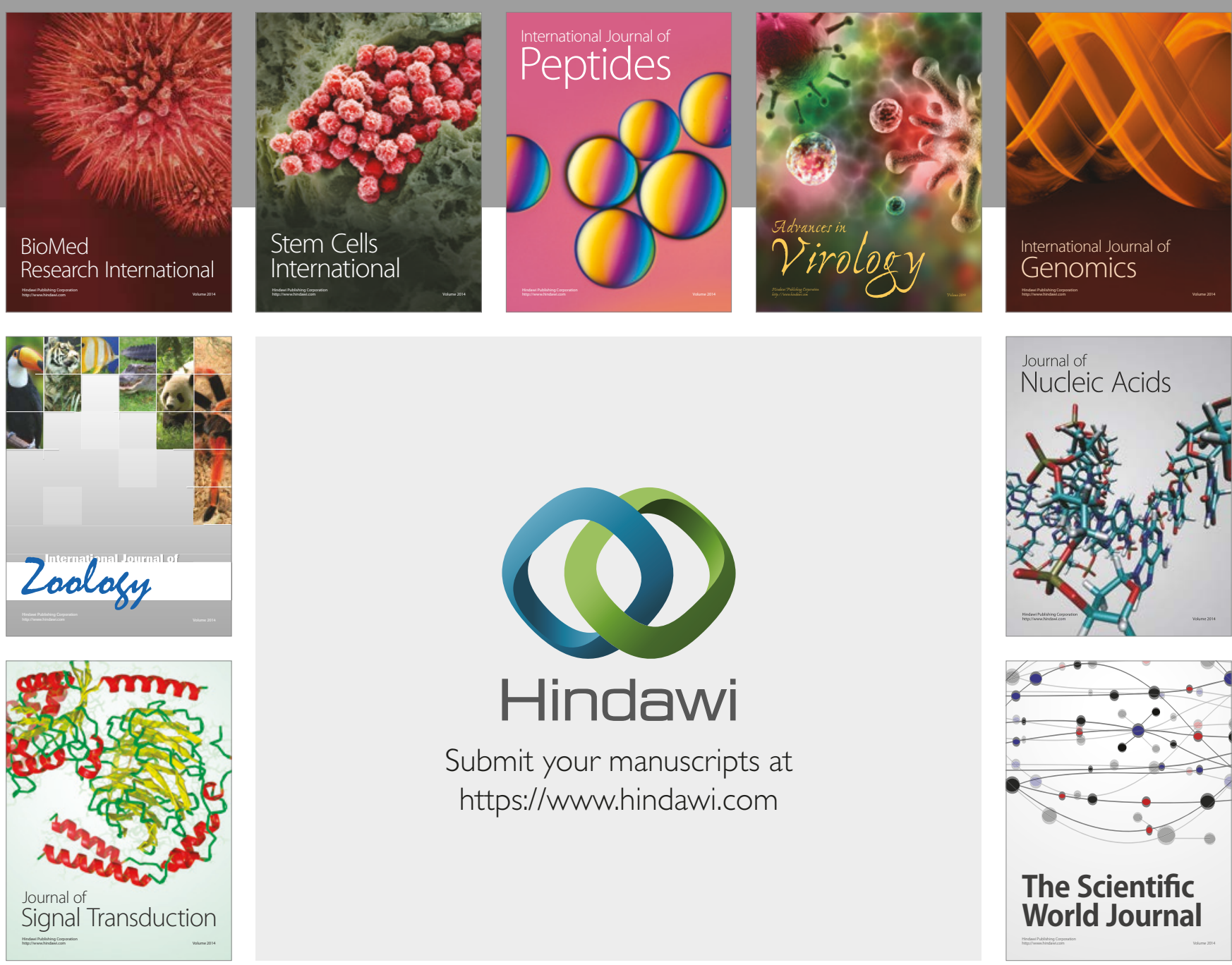

Submit your manuscripts at

https://www.hindawi.com
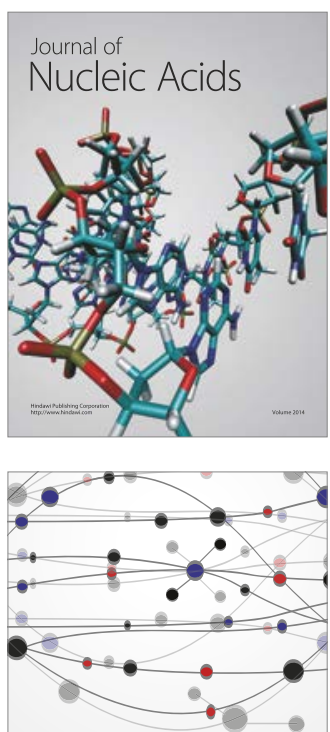

The Scientific World Journal

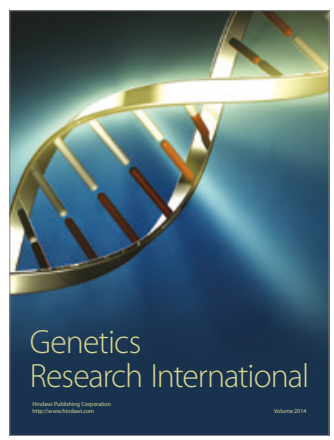

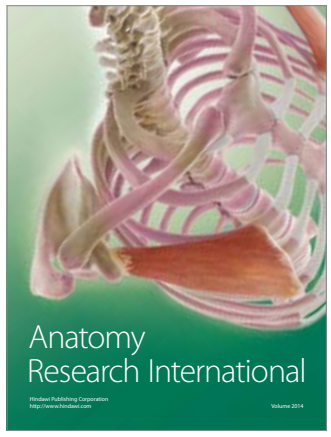

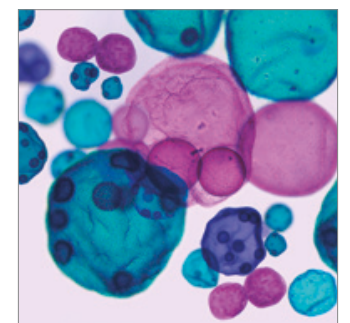

International Journal of Microbiology
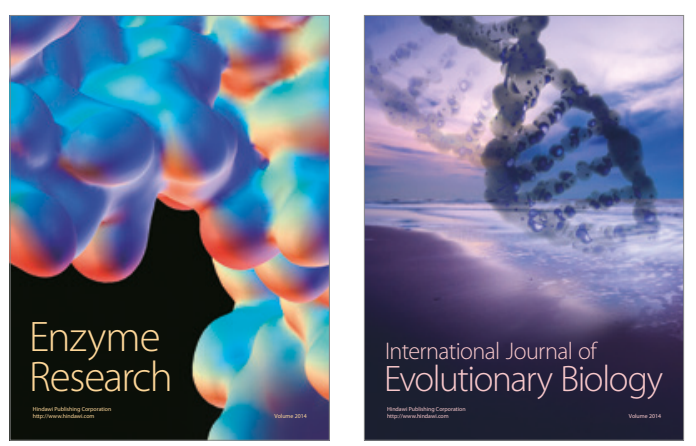
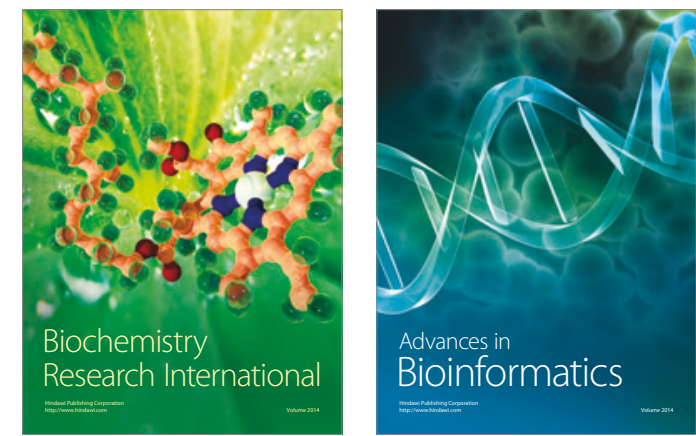

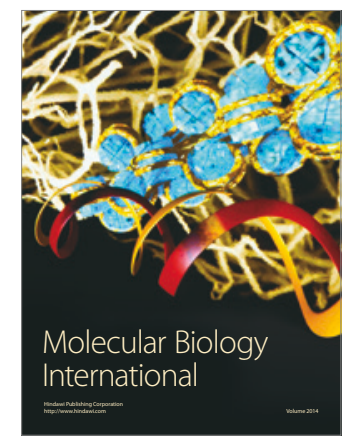

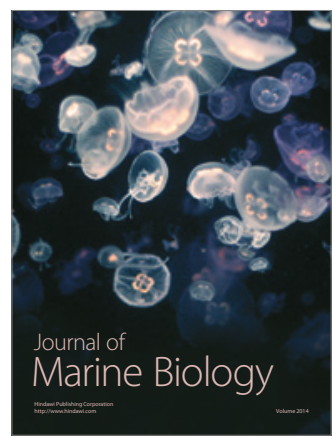

